\title{
REAP: A two minute cell fractionation method
}

\author{
Keiko Suzuki ${ }^{1}$, Pinaki Bose ${ }^{1}$, Rebecca YY Leong-Quong ${ }^{1}$, Donald J Fujita ${ }^{1}$, Karl Riabowol ${ }^{1,2^{*}}$
}

\begin{abstract}
Background: The translocation or shuttling of proteins between the nucleus and cytoplasm (nucleocytoplasmic transport [NCPT]) is often a rapid event following stimulation with growth factors or in response to stress or other experimental manipulations. Commonly used methods to separate nuclei from cytoplasm employ lengthy steps such as density gradient centrifugation which exposes cells to non-physiological hyperosmotic conditions for extended time periods resulting in varying degrees of leakage between the nucleus and cytoplasm. To help maintain and quantify nuclear:cytoplasmic ratios of proteins, agents such as leptomycin B have been employed to be able to better analyze NCPT by inhibiting nuclear export. To track NCPT in the absence of these experimental manipulations that could introduce unknown artefacts, we have developed a rapid method that appears to produce pure nuclear and cytoplasmic fractions, suitable for obtaining accurate estimates of the nuclear: cytoplasmic ratios of proteins known to undergo NCPT.

Findings: We have developed a Rapid, Efficient And Practical (REAP) method for subcellular fractionation of primary and transformed human cells in culture. The REAP method is a two minute non-ionic detergent-based purification technique requiring only a table top centrifuge, micro-pipette and micro-centrifuge tubes. This inexpensive method has proven to efficiently separate nuclear from cytoplasmic proteins as estimated by no detectible cross-contamination of the nucleoporin and lamin A nuclear markers or the pyruvate kinase and tubulin cytoplasmic markers. REAP fractions also mirrored TNF $\alpha$ induced NF- $\kappa$ B NCPT observed in parallel by indirect immunofluorescence.

Conclusions: This method drastically reduces the time needed for subcellular fractionation, eliminates detectable protein degradation and maintains protein interactions. The simplicity, brevity and efficiency of this procedure allows for tracking ephemeral changes in subcellular relocalization of proteins while maintaining protein integrity and protein complex interactions.
\end{abstract}

\section{Findings}

Subcellular fractionation was first described by Albert Claude in 1946 [1,2]. He wrote: "The physiology of the cell cannot be fully understood unless we succeed in determining the constitution of its parts,..." [2]. Subsequently, Claude's method was improved upon by Hogeboom, Schnieder and Palade to obtain the nuclear fraction which was discarded in Claude's original method along with cell debris [3]. Christian de Duve pioneered the use of sucrose density gradients to fractionate cells in $1951[4,5]$ and subsequent researchers have developed various additional modifications [6-8]. Over the last 60-70 years, cell fractionation has provided

\footnotetext{
* Correspondence: karl@ucalgary.ca

'Department of Biochemistry \& Molecular Biology, Faculty of Medicine, University of Calgary, 3330 Hospital Drive NW, Calgary, T2N 4N1, Canada Full list of author information is available at the end of the article
}

biologists with valuable reagents to provide insight into cellular architecture, composition and function of cellular organelles. The nucleus and the cytoplasm have very distinct macromolecular composition and separation of nuclear and cytosolic fractions is proving very useful for proteomic analysis [9]. A majority of the established methods of subcellular fractionation are based on subtle variations of the sucrose density gradient method, often with addition of detergents to solubilize membrane proteins $[10,11]$. However, most of these methods are time consuming and may not be necessary when examining protein localization and complex formation in the nucleus and cytoplasm in cultured cells. Here we introduce a Rapid Efficient And Practical (REAP) nuclear/ cytoplasmic separation protocol using various cultured cells as the starting material. The results obtained from this procedure have been validated by western blotting
Ciomed Central

C 2010 Riabowol et al; licensee BioMed Central Ltd. This is an Open Access article distributed under the terms of the Creative Commons Attribution License (http://creativecommons.org/licenses/by/2.0), which permits unrestricted use, distribution, and reproduction in any medium, providedthe original work is properly cited. 
with two different nuclear and cytoplasmic markers in four different cell types including primary human diploid fibroblasts (HDF) and have also been used in immunoprecipitation-western analyses with good results. The REAP method also performed well for TNFa induced NF- $\kappa \mathrm{B} \mathrm{NCPT}$, corroborating changes in subcellular localization visualized in parallel by indirect immunofluorescence in mouse embryonic fibroblast cells.

\section{Methods \\ REAP method}

All cells used in this study were obtained from the American Type Culture Collection (ATCC). HeLa (human cervical cancer, ATCC\# CCL-13), HCT116 (human colorectal cancer, ATCC\# CCL-247), HEK293 (adenovirus infected human embryonic kidney, ATCC\# CRL-1573) and HS68 (normal HDF, ATCC\# CRL-1635) cells grown as monolayers in $10 \mathrm{~cm}$ diameter dishes were washed in ice-cold phosphate buffer saline (PBS) $\mathrm{pH}$ 7.4, scraped from culture dishes on ice using a plastic cell scraper and collected in $1.5 \mathrm{ml}$ micro-centrifuge tubes in $1 \mathrm{~mL}$ of ice-cold PBS. After centrifugation (a "pop-spin" for $10 \mathrm{sec}$ in an Eppendorf table top microfuge), supernatants were removed from each sample and cell pellets were resuspended in $900 \mu \mathrm{L}$ of ice-cold $0.1 \%$ NP40 (Calbiochem, CA, USA) in PBS and triturated 5 times using a p1000 micropipette (Gilson, WI, USA). $300 \mu \mathrm{L}$ of the lysate was removed as "whole cell lysate" and $100 \mu \mathrm{L}$ of $4 \times$ Laemmli sample buffer was added to it, then kept on ice until the sonication step. The remaining $(600 \mu \mathrm{L})$ material was centrifuged for $10 \mathrm{sec}$ in $1.5 \mathrm{ml}$ micro-centrifuge tubes and $300 \mu \mathrm{l}$ of the supernatant was removed as the "cytosolic fraction". 100 $\mu \mathrm{L}$ of $4 \times$ Laemmli sample buffer was added to this fraction and boiled for $1 \mathrm{~min}$. After the remaining supernatant was removed, the pellet was resuspended in $1 \mathrm{ml}$ of ice-cold $0.1 \%$ NP40 in PBS and centrifuged as above for $10 \mathrm{sec}$ and the supernatant was discarded. The pellet $(\sim 20 \mu \mathrm{L})$ was resuspended with $180 \mu \mathrm{L}$ of $1 \times$ Laemmli sample buffer and designated as "nuclear fraction". Nuclear fractions and whole cell lysates that contained DNA were sonicated using microprobes (Misonix, NY, USA) at level 2, twice for 5 sec each, followed by boiling for $1 \mathrm{~min} .10 \mu \mathrm{L}, 10 \mu \mathrm{L}$ and $5 \mu \mathrm{L}$ of whole cell lysate, cytoplasmic and nuclear fractions, respectively, were loaded and electrophoresed using sodium dodecyl sulfate polyacrylamide gel electrophoresis (SDS-PAGE) [12] and transferred to nitrocellulose membranes (Pall Life Sciences, FL, USA). Membranes were incubated with anti-pyruvate kinase (Santa Cruz, CA, USA) or anti- $\alpha-$ tubulin (Calbiochem, CA, USA) antibodies as cytoplasmic markers or anti-lamin A (Santa Cruz, CA, USA) or anti-nucleoporin (Santa Cruz, CA, USA) as nuclear markers after blocking with $3 \%$ bovine serum albumin in
$0.1 \%$ tween $20-\mathrm{PBS}$ ( $\mathrm{t}-\mathrm{PBS}$ ). Membranes were washed with $\mathrm{t}-\mathrm{PBS}$ followed by incubation with HRP-conjugated anti-rabbit or anti-mouse secondary antibody. After washing with t-PBS, target protein signals were detected by ECL (GE Healthcare, Buckinghamshire, UK) on Kodak X-ray film.

\section{TNF $\alpha$ treatment and NF- $\kappa$ B NCPT}

Wild-type MEFs (mouse embryonic fibroblast, ATCC\# CRL-2991) were grown in $3 \mathrm{~cm}$ dishes with or without glass cover slips. After $1 \mathrm{ng} / \mathrm{ml} \mathrm{TNF} \alpha$ treatment for 15 min $[13,14]$, cells were harvested by the REAP method as described above. Anti NF- $\kappa \mathrm{B}$ p 65 (Santa Cruz, CA, USA), anti $-\alpha$-tubulin (Calbiochem, CA, USA) and antihnRNP C1/C2 (Santa Cruz, CA, USA) antibodies were used for western-blotting analysis. For immunofluorescence, cells grown on cover slips were fixed with methanol and processed as previously described [15]. Briefly, fixed cells were incubated with rabbit anti NF- $\kappa \mathrm{B}$ p65 (Santa Cruz, CA, USA) after blocking with 3\% BSA, then washed with $t$-PBS, followed by Alexa-conjugated anti-Rabbit IgG (Invitrogen, Oregon, USA) incubation. After washing with t-PBS, nuclei were stained by 4',6'Diamidino-2-phenylindole (DAPI) to visualize DNA.

\section{Results}

Immunoblotting results from HeLa, HCT116, HEK293 and HS68 cells are shown in Figure 1, panels A, B, C and $\mathrm{D}$, respectively. Bands corresponding to all the marker proteins were observed in whole cell lysates in each of the four cell types with no cross contamination between nuclear and cytoplasmic fractions and negligible protein degradation. For example, the nuclear markers nucleoporin in Hela cells and lamin A in HCT116, HEK293 and HS68 cells, were not detected in cytoplasmic fractions. Conversely, the cytoplasmic markers (pyruvate kinase and tubulin) were not detected in nuclear fractions.

We next wished to test whether the REAP method would faithfully reflect subcellular localization and alterations in subcellular localization looking at a protein known to partition between the nucleus and cytoplasm. TNF $\alpha$-induced NF- $\kappa$ B translocalization was tracked in parallel using the REAP method followed by western blotting and compared to indirect immunofluorescence. NF- $\kappa$ B was primarily cytoplasmic in unstimulated cells (Figure 2A, left panel), but significant amounts were observed to translocate from the cytoplasm to nucleus after TNF $\alpha$ stimulation (Figure 2A, right panel). Blotting of REAP fractions (Figure 2B) showed that nuclear (snRNP staining) and cytoplasmic ( $\alpha$-tubulin staining) fractions showed little if any crosscontamination consistent with results in Figure 1. Furthermore, a significant amount of NF- $\kappa \mathrm{B}$ was seen in 


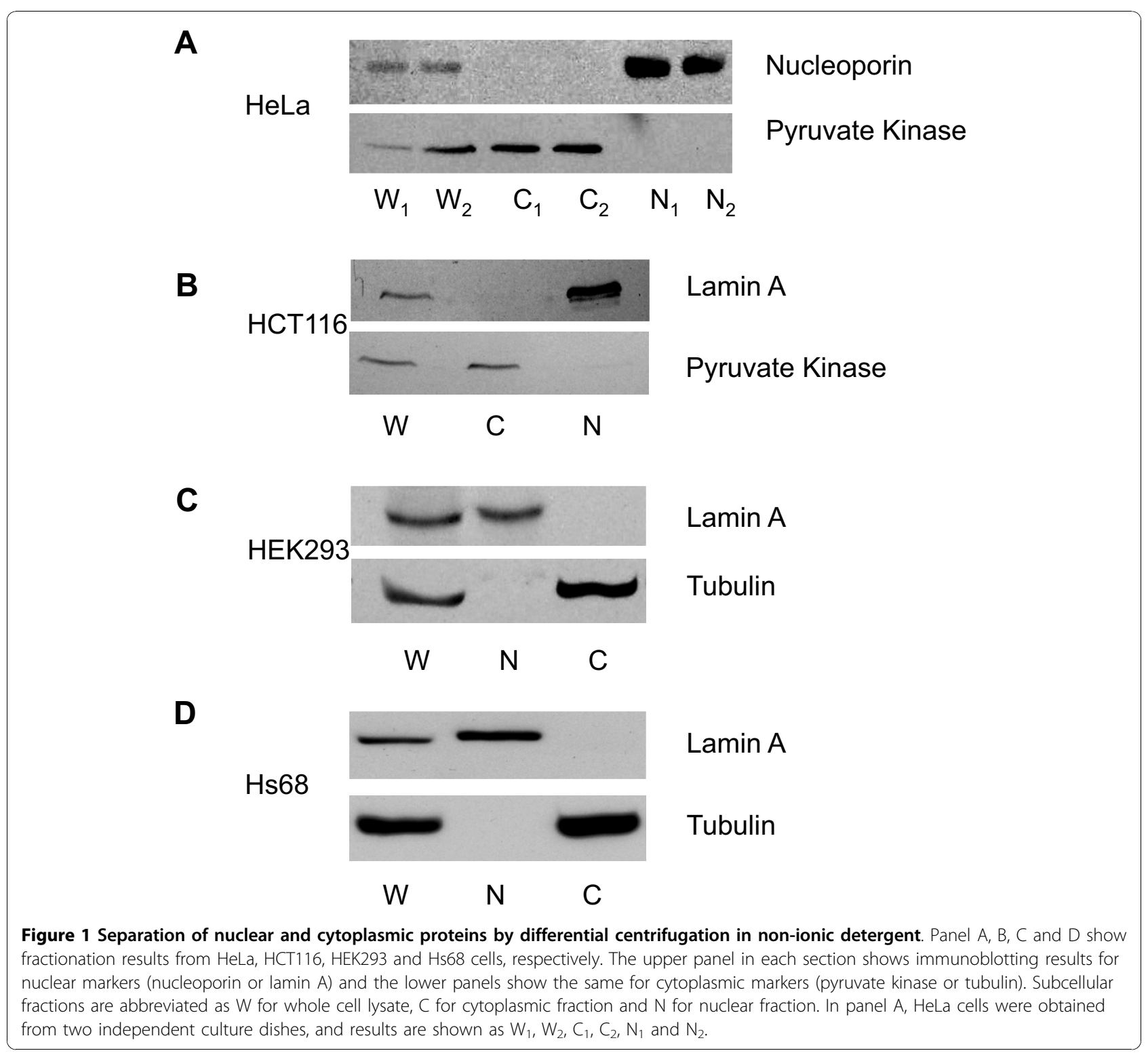

the nucleus after, but not before TNF $\alpha$ stimulation, consistent with immunofluorescence results.

Processing times and required reagents for this REAP method are compared with a standard sucrose density gradient procedure taken from the Laboratory Handbook-Cell Biology [16] in Figure 2. Since homogenization and sucrose gradient layering steps are not required in the REAP protocol and centrifugation times are significantly shorter in the method, we have decreased the handling time to approximately 2 versus 20 minutes compared to this standard sucrose density gradient method. This decrease in processing time significantly reduces protein degradation, enhancing the probability of detection of proteins with short half-lives or marginal solubility and helps maintain protein complexes in nuclear and cytoplasmic samples. Low concentrations of non-ionic detergent $(0.1 \%)$ disrupt cytoplasmic, but not nuclear membranes, and short centrifugation times allow intact nuclei to be pelleted leaving soluble cytosolic proteins in the supernatant. Increasing the detergent concentration to $0.5 \%$ leads to the contamination of cytoplasmic samples with nuclei (data not shown), due to the permeabilization of nuclei at higher detergent levels. Modified versions of this method using combinations of non-ionic detergents such as $0.05 \%$ NP40 and $0.05 \%$ Tween 20 have been successfully used for examination of protein-protein interactions by co-immunoprecipitation-western analyses for both nuclear [17] and cytoplasmic [15] proteins indicating that solubility is also maintained. These reports support the idea that low 


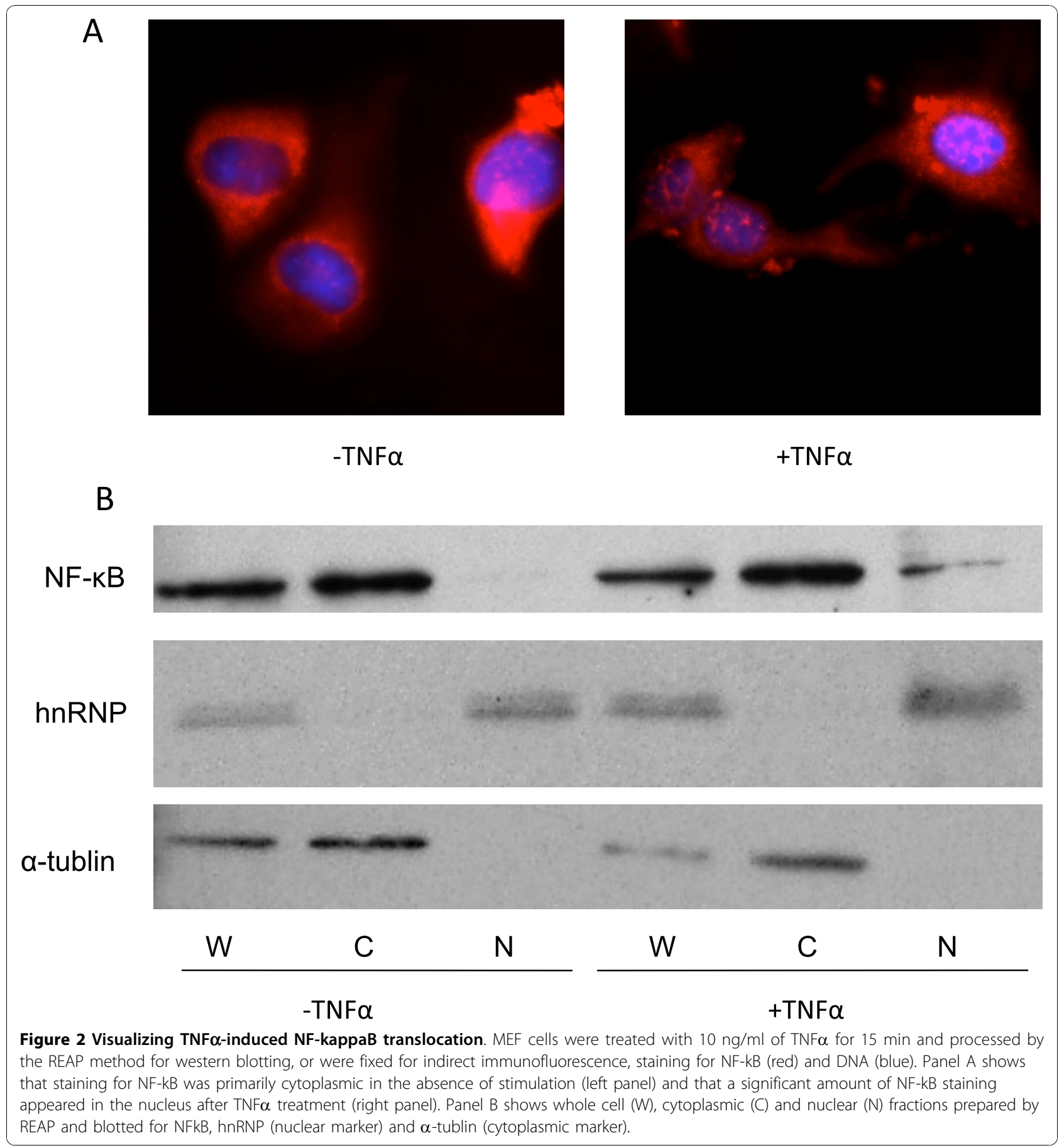

detergent concentrations combined with modest mechanical shear forces generated by trituration are effective for very rapid nuclear-cytoplasmic fractionation which maintain protein and protein complex integrity.

\section{Conclusions}

We have developed and optimized a rapid and simple method for preparing nuclear and cytoplasmic fractions from cultured normal and transformed cells that requires no specialized equipment (see itemized Protocol in Figure 3). This procedure maintains nuclear and cytoplasmic localization, protein integrity, integrity of protein complexes and solubility, indicating that it should be applicable to many experimental questions. Reagents required and a step-by-step outline are provided in Additional File 1. The REAP method provides 


\begin{tabular}{|c|c|c|c|}
\hline Sucrose gradient method & & \multicolumn{2}{|l|}{ REAP method } \\
\hline \multicolumn{4}{|c|}{ Procedure and Time Needed } \\
\hline $\begin{array}{c}\text { Harvest \& resuspend cells } \\
\qquad\end{array}$ & $30 \mathrm{sec}$. & $\begin{array}{c}\text { Harvest \& resuspend cells in } 0.1 \% \text { NP40-PBS } \\
\downarrow\end{array}$ & $30 \mathrm{sec}$. \\
\hline $\begin{array}{c}\text { Homogenize } \\
\downarrow\end{array}$ & $3 \mathrm{~min}$. & $\begin{array}{l}\text { Centrifuge } \\
\downarrow\end{array}$ & $10 \mathrm{sec}$. \\
\hline $\begin{array}{l}\text { Underlay } 40 \% \text { sucrose } \\
\downarrow\end{array}$ & $1 \mathrm{~min}$. & $\begin{array}{l}\text { Wash } \\
\downarrow\end{array}$ & $30 \mathrm{sec}$. \\
\hline$\underset{\substack{\text { Centrifuge } \\
\downarrow}}{ }$ & $15 \mathrm{~min}$. & $\begin{array}{c}\text { Centrifuge } \\
\downarrow\end{array}$ & $10 \mathrm{sec}$. \\
\hline \multirow[t]{2}{*}{ Resuspend pelleted nucle } & $30 \mathrm{sec}$. & Resuspend pelleted nuclei & $30 \mathrm{sec}$. \\
\hline & $20 \mathrm{~min}$. & & $1.3 \mathrm{~min}$. \\
\hline \multicolumn{4}{|c|}{ Special Reagents } \\
\hline \multirow[t]{2}{*}{ Sucrose } & \multicolumn{3}{|c|}{$0.1 \%$ NP40 } \\
\hline & \multicolumn{3}{|c|}{ Special Equipment } \\
\hline $\begin{array}{l}\text { Refrigerated centrifuge } \\
\text { Homogenizer }\end{array}$ & \multicolumn{3}{|c|}{ Table top centrifuge } \\
\hline \multicolumn{4}{|c|}{$\begin{array}{l}\text { Figure } 3 \text { Comparative flowchart of sucrose gradient method and the non-ionic detergent method. The procedures are compared } \\
\text { regarding the time, reagents and equipment required for both methods. }\end{array}$} \\
\hline
\end{tabular}

clear advantages, particularly for the analysis of protein subcellular relocalization and protein complex interactions.

\section{List of Abbreviations}

Abbreviations used include: ATCC: American Type Culture Collection; ECL: Enhanced ChemiLuminesence; HDF: Human Diploid Fibroblasts; HRP: HorseRadish Peroxidase; NCPT: NucleoCytoPlasmic Transport; NF$\kappa$ B: Nuclear Factor kappa B; PBS: Phosphate-Buffered Saline; REAP: a Rapid, Efficient And Practical method for subcellular fractionation; SDS-PAGE: Sodium Dodecyl Sulfate PolyAcrylamide Gel Electrophoresis.

\section{Declaration of Competing interests}

The authors declare that they have no competing interests.

\section{Additional material}

Additional file 1: Protocol for REAP nuclear/cytoplasmic

fractionation. The reagents, equipment needed, procedure and solution recipes are outlined in a printable format suitable for lab use.

Acknowledgements

We thank S. Robbins for kindly providing TNF $\alpha$, and W. Gong and L. Yu for technical support and helpful suggestions. This work was supported by grants to KR from the Canadian Institutes of Health Research and Canadian Breast Cancer Foundation and to DF from the Alberta Cancer Board and Canadian Breast Cancer Foundation. PB is supported by a studentship from the Alberta Cancer Board and KR is a scientist of Alberta Innovates-Health Solutions.

\section{Author details}

'Department of Biochemistry \& Molecular Biology, Faculty of Medicine, University of Calgary, 3330 Hospital Drive NW, Calgary, T2N 4N1, Canada. ${ }^{2}$ Department of Oncology, Faculty of Medicine, University of Calgary, 3330 Hospital Drive NW, Calgary, T2N 4N1, Canada.

\section{Authors' contributions}

$\mathrm{KS}, \mathrm{PB}$ and RYYLQ generated data shown in the panels of Figure 1, KS and PB wrote the first draft of the manuscript, KS produced Figures 2 and 3 and DF and KR helped to conceive and design experiments and write the manuscript. All authors read and approved the final manuscript.

Received: 26 May 2010 Accepted: 10 November 2010 Published: 10 November 2010

\section{References}

1. Claude A: Fractionation of mammalian liver cells by differential centrifugation: I. Problems, methods, and preparation of extract. J Exp Med 1946, 84:51-59.

2. Claude A: Fractionation of mammalian liver cells by differential centrifugation: II. Experimental procedures and results. J Exp Med 1946, 84:61-89.

3. Hogeboom GH, Schneider WC, Pallade GE: Cytochemical studies of mammalian tissues; isolation of intact mitochondria from rat liver; some biochemical properties of mitochondria and submicroscopic particulate material. J Biol Chem 1948.

4. Berthet J, de Duve C: Tissue fractionation studies. I. The existence of a mitochondria-linked, enzymically inactive form of acid phosphatase in rat-liver tissue. Biochem J 1951, 50:174-181. 
5. de Duve C, Pressman BC, Gianetto R, Wattiaux R, Appelmans F: Tissue fractionation studies. 6 . Intracellular distribution patterns of enzymes in rat-liver tissue. Biochem J 1955, 60:604-617.

6. Blobel G, Potter VR: Nuclei from rat liver: isolation method that combines purity with high yield. Science. 1966, 154:1662-1665.

7. de Duve C, Beaufay $\mathrm{H}$ : A short history of tissue fractionation. $J$ Cell Biol 1981, 91:293s-299s.

8. Bronfman M, Loyola G, Koenig CS: Isolation of intact organelles by differential centrifugation of digitonin-treated hepatocytes using a table Eppendorf centrifuge. Anal Biochem 1998, 255:252-256.

9. $\operatorname{Cox} B$, Emili A: Tissue subcellular fractionation and protein extraction for use in mass-spectrometry-based proteomics. Nat Protoc 2006, 1:1872-1878.

10. Hymer WC, Kuff EL: Isolation of nuclei from mammalian tissues through the use of triton X-100. J Histochem Cytochem 1964, 12:359-363.

11. Fleischer B, Smigel M: Solubilization and properties of galactosyltransferase and sulfotransferase activities of golgi membranes in triton X-100. J Biol Chem 1978, 253:1632-1638.

12. Laemmli UK: Cleavage of structural proteins during the assembly of the head of bacteriophage T4. Nature 1970, 227:680-685.

13. Huang $T$, Kudo $N$, Yoshida M, Miyamoto S: A nuclear export signal in the $\mathrm{N}$-terminal regulatory domain of IkappaBalpha controls cytoplasmic localization of inactive NF-kappaB/lkappaBalpha complexes. Proc Natl Acad Sci USA 2000, 97:1014-1019.

14. Takeda Y, Ichikawa H, Pataer A, Swisher S, Aggarwal BB: Genetic deletion of PKR abrogates TNF-induced activation of ljBa kinase, JNK, Akt and cell proliferation but potentiates p44/p42 MAPK and p38 MAPK activation. Oncogene 2007, 26:1201-1212.

15. Gong W, Russell M, Suzuki K, Riabowol K: Subcellular targeting of p33ING1b by phosphorylation-dependent 14-3-3 binding regulates p21WAF1 expression. Mol Cell Biol 2006, 26:2947-2954.

16. Kihlmark M, Hallberg E: Preparation of nuclei and nuclear envelopes. In Cell Biology, a laboratory handbook.. second edition. Edited by: Celis JE. San Diego: Academic Press; 1998:152-158.

17. Scott M, Bonnefin P, Vieyra D, Boisvert FM, Young D, Bazett-Jones DP, Riabowol K: UV-induced binding of ING1 to PCNA regulates the induction of apoptosis. J Cell Sci 2001, 114:3455-3462.

doi:10.1186/1756-0500-3-294

Cite this article as: Suzuki et al.: REAP: A two minute cell fractionation method. BMC Research Notes 2010 3:294.

\section{Submit your next manuscript to BioMed Central and take full advantage of:}

- Convenient online submission

- Thorough peer review

- No space constraints or color figure charges

- Immediate publication on acceptance

- Inclusion in PubMed, CAS, Scopus and Google Scholar

- Research which is freely available for redistribution

Submit your manuscript at www.biomedcentral.com/submit
C Biomed Central 